Gut, 1974, 15, 714-719

\title{
Gastric acid secretion and risk of recurrence of duodenal ulcer within six to eight years after truncal vagotomy and drainage
}

\section{O. KRONBORG ${ }^{1}$}

From the Department of Surgical Gastroenterology A, Bispebjerg Hospital, Copenhagen, Denmark

SUMMARY The value of insulin and augmented histamine tests in predicting recurrence of duodenal ulcer within six to eight years after truncal vagotomy and drainage was assessed in a series of 500 consecutively and electively operated patients. Criteria of recurrence were established by a discriminative analysis of gastric acid secretion parameters. Recurrence was predicted with a probability of about $75 \%$ in patients with dyspepsia, the proportion between recurrences and dyspeptic nonrecurrences being 1:1. The discriminatory ability of the insulin test was no better than that of the postoperative histamine test. Men with a preoperative PAO $>46.1 \mathrm{~m}$-equiv/h had a risk of recurrence of $21 \%$, women with a PAO > $41.5 \mathrm{~m}$-equiv/h, $28 \%$. Below these levels the risk was 5 and $1 \%$ respectively, demonstrating that recurrence after vagotomy is related to the number of parietal cells before vagotomy. A rationale is provided for antrectomy and vagotomy in duodenal ulcer patients with a high number of parietal cells.

It has been stated that the appropriate surgical treatment for duodenal ulcer may be selected by means of gastric acid secretion measurements (Bruce, Card, Marks, and Sircus, 1959; Gillespie and Kay, 1961; Small, Bruce, Falconer, Sircus, and Smith, 1967; Dinstl, 1969), presuming a relationship between preoperative acid secretion and the risk of recurrent ulcer after different operations.

Clark, Murray, Slessor, and Wyllie (1964) found that the augmented histamine test was of no use in predicting the risk of recurrence after vagotomy, but this conclusion was founded on an incomplete follow up of only 149 men and women with 'complete vagotomies', including six recurrences. Cowley, Spencer, and Baron (1973) also found that the preoperative histamine test was useless in predicting recurrence in duodenal ulcer patients, selected by means of postvagotomy insulin test results.

Previous studies by Kronborg (1971a, 1972a, 1973b) demonstrated relationships between the risk of recurrence within three to four years after vagotomy for duodenal ulcer and both pre- and postoperative acid secretion. The present study is a re-

${ }^{1}$ Correspondence to Ole Kronborg, Kajerödvej 124, 3460 Birkeröd, Denmark.

Received for publication 15 May 1974. evaluation of these relationships at a follow-up study of the same 500 patients after six to eight years in an attempt to predict recurrence and to find a rationale for its prevention.

\section{Patients and Methods}

Five hundred patients with duodenal ulcer (DU) were operated upon, electively and consecutively by truncal vagotomy (TV) and pyloroplasty according to the technique of Heineke Miculicz $(\mathrm{P}(\mathrm{HM}))$ or gastrojejunostomy (GJ) from 1963 to 1967. A complete follow-up study was made three to four years after the operation and published with a detailed description of preoperative findings (Kronborg, 1971b). It was repeated six to eight years after the operation (table I).

The expression 'dyspepsia' was used to mean epigastric pain and/or acid eructations and heartburn. Recurrence was considered present when at least one of the following criteria was satisfied: (1) radiologically demonstrated duodenal or gastrojejunal ulcer or pyloric stenosis; (2) dyspepsia with melaena or haematemesis; (3) recurrent or persisting dyspepsia with reduced working capacity.

Endoscopical evidence of recurrent ulcer was only present during the last follow-up study and was not 


\begin{tabular}{|c|c|c|c|c|}
\hline & \multicolumn{2}{|l|}{ No. of Men } & \multicolumn{2}{|l|}{ No. of Women } \\
\hline & $T V+P(H M)$ & $T V+G J$ & $T V+P(H M)$ & $T V+G J$ \\
\hline $\begin{array}{l}\text { No dyspepsia } \\
\text { Dyspepsia, but no recurrence } \\
\text { Recurrence } \\
\text { Gastric ulcer } \\
\text { Died during follow up } \\
\text { Lost to follow up }\end{array}$ & $\begin{array}{r}200 \\
37 \\
33 \\
3 \\
36 \\
4\end{array}$ & $\begin{array}{r}47 \\
2 \\
3 \\
0 \\
11 \\
0\end{array}$ & $\begin{array}{r}67 \\
23 \\
6 \\
1 \\
7 \\
0\end{array}$ & $\begin{array}{r}13 \\
2 \\
1 \\
1 \\
3 \\
0\end{array}$ \\
\hline Total & 313 & 63 & 104 & 20 \\
\hline
\end{tabular}

Table I Follow up of 500 duodenal ulcer patients six to eight years after truncal vagotomy and drainage

included among the criteria of recurrence. Recurrence was considered an indication for reoperation, but a recurrent ulcer crater was actually seen in 27 of the 39 patients undergoing reoperation (table Four patients refused reoperation, three of these II). having radiological signs of duodenal ulcer. The age distribution in patients with recurrence was similar to that in the remaining patients. Fifteen recurrences were diagnosed between the two follow ups, nine having no symptoms and six having dyspepsia at the first follow up.

\begin{tabular}{|c|c|c|c|}
\hline & $\begin{array}{l}\text { No. of } \\
\text { Patients }\end{array}$ & $\begin{array}{l}\text { Cardiac Region } \\
\text { Explored }\end{array}$ & $\begin{array}{l}\text { Persisting Big } \\
\text { Vagal Nerves }\end{array}$ \\
\hline $\begin{array}{l}\text { Duodenal ulcer } \\
\text { Gastrojejunal ulcer } \\
\text { Duodenal scar } \\
\text { Pyloric stenosis } \\
\text { No pathology }\end{array}$ & $\begin{array}{r}24 \\
3 \\
4 \\
4 \\
4\end{array}$ & $\begin{array}{r}10 \\
0 \\
4 \\
3 \\
2\end{array}$ & $\begin{array}{l}\mathbf{6} \\
\mathbf{0} \\
\mathbf{3} \\
\mathbf{3} \\
\mathbf{2}\end{array}$ \\
\hline Total & 39 & 19 & 14 \\
\hline
\end{tabular}

Table II Findings at reoperation for recurrence after truncal vagotomy + drainage for duodenal ulcer

The augmented histamine and insulin tests used have already been described, as well as the expression of the results (Kronborg, 1970). The original dosage of insulin was $0.4 \mathrm{IU}$ per $\mathrm{kg}$ body weight intravenously (Hirschowitz and O'Leary, 1964) and this dosage was also used at the follow up for comparison of the results. Among the $\mathbf{4 3 9}$ patients remaining at the last follow up, 437 had a preoperative histamine test and 424 a histamine test about 10 days after truncal vagotomy. A successful insulin test was performed in 398 patients 10 days after truncal vagotomy and it was repeated three to four years later in 373 patients. (The interval between the two tests was less than three years in 11 of the recurrences, the last test being performed immediately before reoperation.) The five patients with gastric ulcer after truncal vagotomy were excluded.

The discriminative analysis of secretion test parameters has also been described previously (Kronborg, 1971a). The criteria, based on measurements of spontaneous insulin-, and histamine-activated acid secretion were chosen so as to place the highest possible proportion of recurrences and non-recurrences correctly in relation to a critical level of secretion. Values above this level represent a positive criterion of recurrence. The statistical significance was tested by the chi square test with Yates' correction. Recurrences were compared with all nonrecurrences and with dyspeptic non-recurrences alone. Four expressions, as defined by Vecchio (1966), were used when a significant difference was found in proportions of recurrences between the two sides of a critical level, namely, 'specificity', the percentage of patients without recurrence having a negative criterion; 'sensitivity', the percentage of patients with recurrence having a positive criterion; 'predictive value of a negative criterion' $\left(\mathrm{PV}_{\mathrm{neg}}\right)$, the percentage of patients with a negative criterion not having recurrence; and "predictive value of a positive criterion' $\left(\mathrm{PV}_{\mathrm{pos}}\right)$, the percentage of patients with a positive criterion having recurrence.

Acid secretion results were not considered as an indication for operation, either before the original truncal vagotomy or at reoperation for recurrence.

The unpaired $t$ test was used to compare mean values and $P$ values were obtained from Documenta Geigy.

\section{Results}

The preoperative peak acid output after histamine (PAO) was significantly higher in patients with later recurrence than in other patients (table III). The maximum acidity after histamine was also significantly higher in recurrences than in non-recurrences, but the acidity was not significantly lower in dyspeptic non-recurrences than in recurrences ( $P_{m e n}>$ 0.05 , Pwomen $>0 \cdot 10$ ). Peak acid output as well as maximum acidity were significantly higher 10 days after truncal vagotomy in patients with later recurrence than in other patients. The percentage reduction of PAO was less in men with recurrence than 


\begin{tabular}{|c|c|c|c|c|c|c|}
\hline & \multicolumn{3}{|l|}{ Men } & \multicolumn{3}{|l|}{ Women } \\
\hline & No Dyspepsia & Dyspepsia & Recurrence & No Dyspepsia & Dyspepsia & Recurrence \\
\hline $\begin{array}{l}\text { Before truncal vagotomy } \\
\text { n } \\
\text { PAO (mean value m-equiv/h) } \\
\text { SE } \\
\text { Maximum acidity (m-equiv/l) } \\
\text { SE }\end{array}$ & $\begin{array}{r}246 \\
43.2 \\
0.8 \\
111.4 \\
0.9\end{array}$ & \begin{tabular}{r}
\multicolumn{1}{c}{38} \\
44.5 \\
2.1 \\
112.0 \\
2.6
\end{tabular} & \begin{tabular}{r}
\multicolumn{1}{l}{36} \\
$52 \cdot 8$ \\
$2 \cdot 2$ \\
$118 \cdot 1$ \\
1.9
\end{tabular} & $\begin{array}{r}80 \\
31 \cdot 7 \\
1 \cdot 2 \\
104.3 \\
1 \cdot 7\end{array}$ & $\begin{array}{r}25 \\
28.8 \\
1.4 \\
108.1 \\
2.7\end{array}$ & $\begin{array}{r}7 \\
45.4 \\
5.3 \\
117.5 \\
4.9\end{array}$ \\
\hline $\begin{array}{l}\text { Ten days after truncal vagotomy } \\
\text { n } \\
\text { PAO (mean value m-equiv/h) } \\
\text { SE } \\
\text { Maximum acidity (m-equiv/l) } \\
\text { SE } \\
\text { Percentage reduction of PAO (mean value } \\
\text { in per cent) } \\
\text { SE }\end{array}$ & $\begin{array}{r}238 \\
16 \cdot 6 \\
0 \cdot 5 \\
82 \cdot 7 \\
1 \cdot 5 \\
\\
61 \cdot 7 \\
1 \cdot 0\end{array}$ & 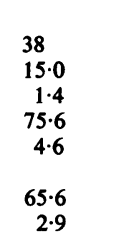 & 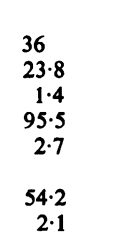 & $\begin{array}{r}75 \\
11 \cdot 9 \\
0 \cdot 8 \\
71 \cdot 2 \\
3 \cdot 1 \\
\\
62 \cdot 9 \\
2 \cdot 2\end{array}$ & \begin{tabular}{r|r}
\multicolumn{1}{c}{25} \\
$11 \cdot 8$ \\
$0 \cdot 8$ \\
$79 \cdot 8$ \\
$3 \cdot 6$ \\
\\
$58 \cdot 8$ \\
$2 \cdot 3$
\end{tabular} & $\begin{array}{r}7 \\
22 \cdot 0 \\
4 \cdot 0 \\
101 \cdot 8 \\
5 \cdot 7 \\
\\
50 \cdot 6 \\
5 \cdot 6\end{array}$ \\
\hline
\end{tabular}

Table III The augmented histamine test result related to six to eight years of follow up after truncal vagotomy

in other men, while this difference was insignificant in women $(P>0 \cdot 10)$.

The risk of recurrence in men with a preoperative PAO > 46.1 m-equiv/h was $21 \%$, while men with a lower PAO had a risk of $5 \%$ (table IV). The critical level in women was $41.5 \mathrm{~m}$-equiv/h. The risk was $25 \%$ in men with PAO $>20.7$ m-equiv/h after truncal vagotomy and only $5 \%$ below this level. The level after truncal vagotomy was $18.7 \mathrm{~m}$-equiv/h in women. The discriminatory ability of the percentage reduction of PAO was also significant, the critical level being 68.3 in men and 61.4 in women.

A comparison of men with recurrence and those with dyspepsia but no recurrence resulted in unchanged critical levels, an increase of $\mathbf{P V}_{\text {pos }}$ and a decrease of $\mathbf{P V}_{\text {neg }}$ (table IV). Maximum acidity seemed to have a less discriminatory ability than PAO before and after truncal vagotomy according to chi square values.

The $\mathbf{P V}_{\text {pos }}$ of insulin tests 10 days after truncal vagotomy (table $\mathrm{V}$ ) ranged from 22 to $32 \%$ in men and 16 to $33 \%$ in women, comparing recurrences

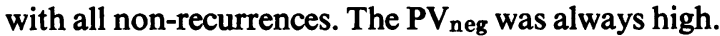
The Hollander response had a low discriminatory ability, the sensitivity being $45 \%$ in men. The $P_{\text {pos }}$ was increased and $\mathbf{P V}_{\text {neg }}$ decreased for all criteria when recurrences and dyspeptic non-recurrences were compared. Criteria based on increase of acid secretion after insulin were no better than those based on spontaneous or insulin-activated secretion.

Men with a positive Hollander response 10 days after truncal vagotomy had a higher $(\mathrm{P}<0.001)$ postoperative mean PAO (21 m-equiv/h) than men with a negative response $(16 \mathrm{~m}$-equiv/h). The latter had a mean percentage reduction of PAO of 64, a higher value $(P<0.001)$ than that in patients with a positive Hollander response $(54 \%)$. The preoperative PAO was not different in patients with positive and negative Hollander responses after truncal vagotomy.

Criteria based on insulin tests three to four years after truncal vagotomy (table VI) were similar to those 10 days after truncal vagotomy according to critical levels, but the sensitivity was higher and the

\begin{tabular}{|c|c|c|c|c|c|}
\hline Positive Criteria & $x^{2}$ & Specificity (\%) & Sensitivity (\%) & $P V_{n e g}(\%)$ & $P V_{p o s}(\%)$ \\
\hline \multirow{4}{*}{$\begin{array}{l}\text { Before truncal vagotomy } \\
\text { (36 recurrences }+284 \text { non-recurrences) } \\
\text { PAO }>46 \cdot 1 \text { m-equiv/h } \\
\text { Maximum acidity }>119 \text { m-equiv } / 1 \\
\text { ( } 36 \text { recurrences }+38 \text { dyspeptic non-recurrences) } \\
\text { PAO }>46 \cdot 1 \text { m-equiv } / \mathrm{h} \\
\text { Maximum acidity }>119 \text { m-equiv/l }\end{array}$} & & & & & \\
\hline & $11 \cdot 3$ & 71 & 58 & 93 & 20 \\
\hline & $8 \cdot 1$ & 61 & 75 & 72 & 64 \\
\hline & $4 \cdot 3$ & 68 & 58 & 63 & 64 \\
\hline \multirow{7}{*}{$\begin{array}{l}\text { Ten days after truncal vagotomy } \\
\text { ( } 36 \text { recurrences }+276 \text { non-recurrences) } \\
\text { PAO }>20 \cdot 7 \text { m-equiv } / \mathrm{h} \\
\text { Maximum acidity }>70 \text { m-equiv } / 1 \\
\text { Reduction of PAO }<68 \cdot 3 \% \\
\text { (36 recurrences }+38 \text { dyspeptic non-recurrences) } \\
\text { PAO }>20.7 \text { m-equiv } / \mathrm{h} \\
\text { Maximum acidity }>70 \text { m-equiv } / 1 \\
\text { Reduction of PAO }<68.3 \%\end{array}$} & & & & & \\
\hline & $24 \cdot 2$ & 73 & 70 & 95 & 25 \\
\hline & 7.6 & 29 & 94 & 98 & 15 \\
\hline & $11 \cdot 8$ & 36 & 94 & 98 & 16 \\
\hline & $13 \cdot 7$ & 76 & 70 & 73 & 74 \\
\hline & $5 \cdot 4$ & 29 & 94 & 85 & 56 \\
\hline & 11.9 & 43 & 94 & 89 & 62 \\
\hline
\end{tabular}

Table IV Discriminatory ability of the augmented histamine test result before and after truncal vagotomy in men 


\begin{tabular}{|c|c|c|c|c|c|c|c|}
\hline Positive Criteria & $\begin{array}{l}\text { No. of Non- } \\
\text { recurrences }\end{array}$ & $\begin{array}{l}\text { No. of } R e- \\
\text { currences }\end{array}$ & $C h i^{2}$ & $\begin{array}{l}\text { Specificity } \\
(\%)\end{array}$ & $\begin{array}{l}\text { Sensitivity } \\
(\%)\end{array}$ & $\begin{array}{l}P V_{n e g} \\
(\%)\end{array}$ & $\begin{array}{l}P V_{\text {pos }} \\
(\%)\end{array}$ \\
\hline $\begin{array}{l}\text { BAO }>1.3 \text { m-equiv } / \mathrm{h} \\
\text { Mean spontaneous acidity } \geqslant 24.0 \mathrm{~m} \text {-equiv } / 1 \\
\text { PAO(I) }>1.5 \text { m-equiv } / \mathrm{h} \\
\text { Total acid output after insulin }>1.1 \mathrm{~m} \text {-equiv } / 2 \mathrm{~h} \\
\text { Maximum acidity after insulin (MIA) }>31 \mathrm{~m} \text {-equiv } / 1 \\
\text { PAO(I)-BAO }>1.1 \mathrm{~m} \text {-equiv } / \mathrm{h} \\
\text { MIA-mean spontaneous acidity }>17 \text { m-equiv } / 1 \\
\text { Positive Hollander response }\end{array}$ & $\begin{array}{l}247 \\
247 \\
257 \\
257 \\
257 \\
234 \\
234 \\
250\end{array}$ & $\begin{array}{l}30 \\
30 \\
33 \\
33 \\
33 \\
28 \\
28 \\
29\end{array}$ & $\begin{array}{r}14 \cdot 2 \\
27 \cdot 9 \\
27 \cdot 1 \\
27 \cdot 1 \\
30 \cdot 7 \\
8 \cdot 4 \\
10 \cdot 9 \\
8 \cdot 5\end{array}$ & $\begin{array}{l}72 \\
86 \\
76 \\
76 \\
80 \\
82 \\
80 \\
81\end{array}$ & $\begin{array}{l}63 \\
57 \\
70 \\
70 \\
67 \\
43 \\
50 \\
45\end{array}$ & $\begin{array}{l}94 \\
94 \\
95 \\
95 \\
95 \\
92 \\
93 \\
93\end{array}$ & $\begin{array}{l}22 \\
32 \\
27 \\
27 \\
30 \\
23 \\
23 \\
26\end{array}$ \\
\hline
\end{tabular}

No. of Dys- No. of Repeptic Non- currences recurrences

BAO $>1.3$ m-equiv $/ \mathrm{h}$

Mean spontaneous acidity $\geqslant 27.0 \mathrm{~m}$-equiv/l

$\mathrm{PAO}(\mathrm{I})>1.5 \mathrm{~m}$-equiv $/ \mathrm{h}$

Total acid output after insulin $>1 \cdot 1 \mathrm{~m}$-equiv $/ 2 \mathrm{~h}$

MIA > 31 m-equiv/1

PAO(I)-BAO $>1 \cdot 1 \mathrm{~m}$-equiv/h

MIA - mean spontaneous acidity $>17$ m-equiv/l

Positive Hollander response

\begin{tabular}{llrllll}
\hline 32 & 30 & $4 \cdot 1$ & 66 & 63 & 66 & 63 \\
32 & 30 & $9 \cdot 6$ & 84 & 57 & 68 & 77 \\
36 & 33 & $15 \cdot 7$ & 81 & 70 & 74 & 77 \\
36 & 33 & $17 \cdot 7$ & 83 & 70 & 75 & 79 \\
36 & 33 & $15 \cdot 8$ & 86 & 67 & 73 & 79 \\
31 & 28 & $5 \cdot 2$ & 87 & 43 & 63 & 75 \\
31 & 28 & $6 \cdot 2$ & 84 & 50 & 65 & 74 \\
36 & 29 & $6 \cdot 2$ & 86 & 45 & 66 & 72 \\
\hline
\end{tabular}

Table V Discriminatory ability of the insulin test 10 days after truncal vagotomy in men

specificity lower (BAO excepted) than 10 days after truncal vagotomy. Men with a positive Hollander response three to four years after truncal vagotomy and recurrence within six to eight years had a higher $(\mathrm{P}<0.02)$ mean PAO $(52.6 \mathrm{~m}$-equiv/h) before the original operation than men with a positive response but no recurrence $(43.4 \mathrm{~m}$-equiv/h).

Adding the criteria in table VI (multiple criteria) resulted in an increase of $\mathrm{PV}_{\text {pos }}$ from 27 to $53 \%$ when four positive criteria were demanded instead of two; the sensitivity decreased from 93 to $28 \%$ at the same time.

Insulin test results in women are not presented to save space, but they allowed a significant discrimination, both in the early and late postoperative period.
Among the 14 patients with persisting vagal nerves at reoperation (table II) 11 had insulin tests 10 days after truncal vagotomy and before reoperation. A marked increase of acidity ( $>30$ m-equiv/l) after insulin was seen in six of the patients at the first as well as the second test.

Increasing the levels for all histamine and insulin test criteria by not demanding the sum of specificity and sensitivity to be maximum resulted in an increase of $\mathrm{PV}_{\text {pos, }}$, but a marked fall in sensitivity followed.

\section{Discussion}

The risk of recurrence after truncal vagotomy for duodenal ulcer is higher in patients with a large parietal cell mass than in those with a normal or

\begin{tabular}{|c|c|c|c|c|c|c|c|}
\hline Positive Criteria & $\begin{array}{l}\text { No. of Non- } \\
\text { recurrences }\end{array}$ & $\begin{array}{l}\text { No. of } R e- \\
\text { currences }\end{array}$ & $C h i^{2}$ & $\begin{array}{l}\text { Specificity } \\
(\%)\end{array}$ & $\begin{array}{l}\text { Sensitivity } \\
(\%)\end{array}$ & $\begin{array}{l}P V_{n e g} \\
(\%)\end{array}$ & $\begin{array}{l}P V_{p o s} \\
(\%)\end{array}$ \\
\hline $\begin{array}{l}\text { BAO }>1.5 \text { m-equiv } / \mathrm{h} \\
\text { Mean spontaneous acidity } \geqslant 17.0 \text { m-equiv } / 1 \\
\text { PAO(I) }>1.3 \text { m-equiv } / \mathrm{h} \\
\text { Total acid output after insulin }>1.0 \mathrm{~m} \text {-equiv } / 2 \mathrm{~h} \\
\text { Maximum acidity after insulin }(\mathrm{MIA})>31 \mathrm{~m} \text {-equiv } / 1 \\
\text { PAO(I)-BAO }>1.1 \mathrm{~m} \text {-equiv } / \mathrm{h} \\
\text { MIA-mean spontaneous acidity }>20 \mathrm{~m} \text {-equiv } / 1 \\
\text { Positive Hollander response }\end{array}$ & $\begin{array}{l}248 \\
248 \\
245 \\
245 \\
245 \\
245 \\
245 \\
245 \\
\text { No. of Dys- } \\
\text { peptic Non- } \\
\text { recurrences } \\
31 \\
31 \\
31 \\
31 \\
31 \\
31 \\
31 \\
31\end{array}$ & $\begin{array}{l}29 \\
29 \\
29 \\
29 \\
29 \\
29 \\
29 \\
29 \\
\text { No. of } R e- \\
\text { currences } \\
29 \\
29 \\
29 \\
29 \\
29 \\
29 \\
29 \\
29\end{array}$ & $\begin{array}{r}38 \cdot 1 \\
46 \cdot 3 \\
33 \cdot 1 \\
31 \cdot 3 \\
30 \cdot 1 \\
15 \cdot 2 \\
18 \cdot 1 \\
8 \cdot 1\end{array}$ & $\begin{array}{l}79 \\
83 \\
67 \\
66 \\
71 \\
75 \\
69 \\
63\end{array}$ & $\begin{array}{l}76 \\
76 \\
90 \\
90 \\
83 \\
62 \\
72 \\
72\end{array}$ & $\begin{array}{l}97 \\
97 \\
98 \\
98 \\
97 \\
94 \\
96 \\
95\end{array}$ & $\begin{array}{l}30 \\
34 \\
25 \\
24 \\
25 \\
23 \\
22 \\
19\end{array}$ \\
\hline
\end{tabular}

Table VI Discriminatory ability of the insulin test three to four years after truncal vagotomy in men 
small number of parietal cells. This was also true in patients with a positive Hollander response three to four years after truncal vagotomy. It is not surprising that PAO values also had a discriminatory ability after truncal vagotomy, since a strong correlation exists between PAO before and after that operation. However, the higher postoperative PAO values in patients with positive than with negative insulin tests suggest that an incomplete truncal vagotomy may be responsible for recurrence in some of the patients. This is in accordance with the higher percentage reduction of PAO in patients with negative than in patients with positive Hollander responses, confirming that gastric vagal innervation is responsible for a part of the acid secretion activated by histamine. Apparently intact vagal nerves seen at reoperation were not tantamount to a positive Hollander response, which may be due to resection neurinomas overlooked by the surgeon (Kronborg, 1973a). On the other hand, a positive Hollander response, demanding only a small increase in acidity, may be due to factors other than incomplete vagotomy in some of the patients; recent studies (Stadil and Rehfeld, 1973; Kronborg, Pedersen, Stadil, and Rehfeld, 1974) suggest that release of epinephrine by hypoglycaemia may cause a rise in acid secretion. An increase of acidity after insulin of the same magnitude as before truncal vagotomy is more frequent in patients with recurrence after truncal vagotomy than in those without recurrence, indicating that incomplete vagotomy is commoner in the former (Kronborg, 1972b); also a marked increase of acidity is seldom seen after surgical revagotomy.

Moore (1973) made it probable that a high spontaneous acid secretion associated with recurrence was due to non-vagal mediation in some patients after truncal vagotomy, but that study gave, like the present, no clue to the relative importance of vagal and non-vagal mediation for the development of recurrence.

The increase in sensitivity and fall in specificity from early to late insulin tests is related to a small mean increase in insulin-activated secretion and a larger increase in patients with recurrence than in the other patients during the three to four years (Kronborg, 1971c). However, the increasing sensitivity of insulin test criteria with time is of little value because of the small number of recurrences, and the present study does not support the general statement that late tests have a higher predictive value than tests performed during the first two weeks after truncal vagotomy; they have the same low discriminatory ability.

Watkin (1971) found a calculated risk of recurrence of $2.4 \%$ in patients with MIA below 40 m-equiv/l on routine testing, a similar figure to our
$3 \%$ below $31 \mathrm{~m}$-equiv/l. The somewhat high dosage of insulin and the use of $\mathrm{pH} 3.5$ as the titration endpoint in the present study may explain the lower critical level for MIA. Watkin used 0.2 IU of insulin which now is known to produce a higher acid response than $0.4 \mathrm{IU}$ but the difference is very small (Baron and Cowley, 1971; Kronborg, 1972b). The results of the present discrimination are in full agreement with the assumptions made by Watkin in a selected group of duodenal ulcer patients after truncal and selective vagotomy: a recurrence rate of $10 \%$ and a $50 \%$ prior probability of recurrence was presumed in patients tested on account of symptoms, resulting in a risk of recurrence in $18 \%$ below 40 mequiv/l, a similar figure to that in table VI, comparing 29 recurrences and 31 dyspeptic non-recurrences. However, the present acid secretion figures in patients with dyspepsia but no recurrence did not differ from those in patients without dyspepsia, suggesting that the risk of later recurrence may not necessarily be higher in the former group.

The study of Cowley et al (1973) is not comparable to the present one, and is not suitable for the demonstration of possible relationships between recurrence and gastric acid secretion because the patients were selected beforehand by their Hollander responses. Nevertheless, a reduction in PAO of $60 \%$ was found to have discriminatory ability.

An insulin test should probably not be performed routinely, since the less risky histamine test has the same discriminatory ability. Patients with recurrence after truncal vagotomy and a marked rise in acidity after insulin may benefit from an insulin test since a re-vagotomy will lower the acid secretion in most of these patients.

The preoperative histamine test may be valuable in preventing recurrence. It must be emphasized that the risk of recurrence increases with increasing PAO; it is not a sudden onset of risk at a defined level, but the discriminatory analysis separates patients with a high risk from those with a low risk. Forty-one per cent of the men and $19 \%$ of the women had PAO values above the critical level, in accordance with previous findings (Kronborg, 1972a). It is suggested that these patients should be treated with vagotomy and antrectomy, having a very low risk of recurrence, while patients with lower acid secretion should have a vagotomy carrying a risk of recurrence of $5(2-9) \%$ in men and $1 \%(0-6)$ in women.

\footnotetext{
References

Baron, J. H., and Cowley, D. J. (1971). Dose response of gastric acid to insulin in patients with incomplete vagotomy. Brit. J. Surg., 58, 296.

Bruce, J., Card, W. I., Marks, I. N., and Sircus, W. (1959). The ration-
} 
ale of selective surgery in the treatment of duodenal ulcer. $J$. roy. Coll. Surg. Edinb., 4, 85-104.

Clark, C. G., Murray, J. G., Slessor, I. M., and Wyllie, J. H. (1964), Complete vagotomy and its consequences: Follow up of 146 patients. Brit. med. J., 2, 900-903.

Cowley, D. J., Spencer, J., and Baron, J. H. (1973). Acid secretion in relation to recurrence of duodenal ulcer after vagotomy and drainage. Brit. J. Surg., 60, 517-522.

Dinstl, K. (1969). Choice of operations for patients with duodenal ulcers. Surg. Gynec. Obstet. 128, 77-80.

Gillespie, I. E., and Kay, A. W. (1961). Effect of medical and surgical vagotomy on the augmented histamine test. in man Brit. med. $J ., 1,1557-1560$.

Hirschowitz, B. I., and O'Leary, D. K. (1964). Dose dependence of insulin-stimulated gastric secretion. Amer. J. dig. Dis., 9, 379. 397.

Kronborg, O. (1970). Methods and results of repeated insulin tests in patients with duodenal ulcer. Scand. J. Gastroent., 5, 577-583.

Kronborg, O. (1971a). The value of the insulin test in predicting recurrence after vagotomy and drainage for duodenal ulcer. Scand. J. Gastroent., 6, 471-478.

Kronborg, O. (1971b). Truncal vagotomy and drainage in 500 patients with duodenal ulcer. Scand. J. Gastroent., 6, 501-509.

Kronborg, O. (1971c). The stability of the insulin test result after truncal vagotomy and drainage for duodenal ulcer. Scand. $J$. Gastroent., 6, 637-644.

Kronborg, O. (1972a). Influence of the number of parietal cells on risk of recurrence after truncal vagotomy and drainage for duodenal ulcer. Scand. J. Gastroent., 7, 423-431.

Kronborg, O. (1972b). An Evaluation of the Insulin Test, pp. 43, 118. FADLS forlag, Copenhagen.

Kronborg, O. (1973a). A follow up of patients operated upon for recurrence after vagotomy and drainage for duodenal ulcer. Scand. J. Gastroent., 8, 123-128.

Kronborg, O. (1973b). The discriminatory ability of gastric acid secretion tests in the diagnosis of recurrence after truncal vagotomy and drainage for duodenal ulcer. Scand. J. Gastroent., 8, 483489.

Kronborg, O., Pedersen, T., Stadil, F., and Rehfeld, J. F. (1974). The effect of beta-adrenergic blockade upon gastric acid secretion and gastrin secretion during hypoglycaemia before and after vagotomy. Scand. J. Gastroent., 9, 173-176.

Moore, J. G. (1973). High gastric acid secretion after vagotomy and pyloroplasty in man-evidence for nonvagal mediation. Amer. J. dig.Dis., 18, 661-669.

Small, W. P., Bruce, J., Falconer, C. W. A., Sircus, W., and Smith, A. N. (1967). The results of a policy of selective surgical treatment of duodenal ulcer. Brit. J. Surg., 54, 838-841.

Stadil, F., and Rehfeld, J. F. (1973). Release of gastrin by epinephrine in man. Gastroenterology, 65, 210-215.

Watkin, D. F. L. (1971). The delayed insulin test and recurrent duodenal ulceration. Brit. J. Surg., 58, 775-780.

Vecchio, T. J. (1966). Predictive value of a single diagnostic test in unselected populations. New Engl. J. Med., 274, 1171-1173. 